\title{
Public financial management reform: An ongoing journey towards good governance
}

\author{
Fadi Alkaraan \\ Department of Accounting, Finance and Information Systems \\ Cork University Business School \\ University College Cork, Ireland \\ Email: Fadi.Alkaraan@ucc.ie \\ Fadi.Alkaraan@yahoo.com
}

\begin{abstract}
Purpose

This paper provides a better understanding of the influence of contextual factors on public financial management reform (PFMR) process. It provides a comprehensive analytical view of PFMR in the UAE over the period (2003-2016).

\section{Design/methodology/approach}

The paper is based on a case study approach as a research methodology. It draws on archival data as well as interviews with key staff of the Ministry of Finance. A contingency model is used as conceptual framework to examine PFMR in the UAE.

\section{Findings}

Finding of this study show that PFMR process can't be viewed as isolated initiative, rather, as part of a set of broader NPM reforms to strengthen public accountability for performance. The transition process creates major organisational changes; strategy, structure (new rules and roles), culture (core values about organisational vision, mission, and objectives), Benchmarks and milestones have been set in the accompanying monitoring matrix, though in practice delays have typically occurred in the implementation of reforms. Challenges ahead facing the MoF are addressed.
\end{abstract}

\section{Research limitations/implications}

The findings should be understood in the economic, social and historical contexts of the UAE. Given the narrow scope of this paper, a single case study. Crucial themes for future research including how public sector executives employ effective independent measures of outcomes. The impact of basic supporting subsystems in translating strategic priorities and integrating them into the federal budget.

\section{Practical implications}

Research on PFMR is inherently practical. Essential factors for successful implantation of PFMR include government strategy, regulatory framework, information communication technology, technical experience, strong leadership, long-term political and administrative commitments, strategic pre-decision control mechanisms and accurate performance measurement.

\section{Originality/value}

This paper contributes to the limited studies on PFMR in MENA countries. Lessons of this study may be valid for other countries considering similar developments in their PFMR.

Keywords: Public financial management reform, performance based budgeting, transparency, accountability, governance, MENA. 


\section{Public financial management reform: An ongoing journey towards good governance}

\section{Introduction}

The global financial crisis triggered major changes in the approach to financial regulation with the recognition that in order to ensure macroeconomic stability, economic policy has to include financial stability as an additional objective. The crisis highlighted the need for a better understanding of macro financial linkages and underscored the importance of macro prudential policies in addition to micro prudential regulation and supervision, as well as strong fiscal and monetary policy frameworks. Successful public financial management reforms (PFMR) are crucial for effective and sustainable economic management. In recent years, governments in many regions have adopted a wide range of reforms to make fiscal policies more consistent and effective over the medium-term and emphasize the impact of policies and spending. Although not all PFMR have been successful, most have contributed in some way to a gradual advancement of public financial management, especially in developed countries.

Many OECD and EU countries in particular have undertaken public sector accounting and budgeting reforms (PFMR) in the last 30 years (e.g. Australia, New Zealand, USA, Canada, UK, Netherlands, France, Denmark). Also, many emerging economies have followed a similar path (e.g., Russia, Korea, Turkey, South Africa, Chile, and UAE). Performance basedbudgeting (PBB) and medium-term expenditure frameworks have been central elements of PFMR to achieve the 4E's (i.e. economy, efficiency, effectiveness and equity) of greater governance within new public management framework (Bunse and Fritz, 2012).

However, it is widely recognized that developing countries lack accounting research, theories and empirical evidence that explain the contextual factors surrounding PFMR processes (see, Jones, 1991; Boex, 2003; Sarker, 2006; Hopper et al., 2009; Goddard, 2010; Ohenmeng, 2010; Adhikari and Mellemvik, 2011). PFMR is firmly embedded in the political, economic, legal and social contexts (Jorge et al., 2011). This results in the underlying literature, namely comparative international governmental accounting research (CIGAR). Over a 25-year period, comparative international governmental accounting research has constantly revealed the uniqueness of national governments due to the various relations that may exist between their legislatures, executives and judiciaries (Jones et al., 2013). Unique characteristics lead each national government to have its own rules and conventions, and thus its own consequent accounting and budgeting system (Jones et al., 2013). Accordingly, it is essential to understand 
what leads a national government to consider PFMR in an attempt to be more modern; how such PFMR are planned and implemented; and the factors affecting such transition processes.

The journey of PFMR in UAE has been launched by the Ministry of Finance (MoF) since 2004 and is still ongoing. This study provides a comprehensive review of PFMR in UAE and articulates the influence of contextual factors surrounding of PFMR the process. The remainder of this paper is organized in four sections. Section two reviews the existing literature on PFMR. Section three outlines the research methodology and the conceptual framework employed in this study. Section four provides details of PFMR process in UAE over the period (2005-2015). Section five includes discussion and concluding remarks.

\section{Literature review}

Over the past three decades, the performance of governments has been criticised around the world and from all points of the political spectrum due to inefficient, ineffective, too costly, overly bureaucratic, and unresponsive to quality of services deserved by citizens (e.g. Jones \& Kettl, 2003; Hoque \& Adams, 2011; Irvine, 2011; Bracci \& Llewellyn, 2012; Alam \& Holloway, 2012; Kambanei, 2014). New public management has at its roots a theoretical framework that draws upon various economic theories primarily public choice, agency, and transaction cost. The literature on NPM is broad and beyond the scope of this study. For detailed analysis in different jurisdictions, see, e.g. Hood (1991;1995), Guthrie, Olson, and Humphrey (1999), Maor (1999), Manning (2001), Pollitt and Bouckaert (2000), Pallot (1998 and 2001), Hopper and Mserembo, (2004), Newberry and Pallot ( 2004), Ezzamel, Hyndman, Johnsen, Lapsley, and Pallot (2005), Curristine, Lonti, and Joumard (2007), Broadbent and Guthrie (2008), Broadbent and Guthrie (2008), Hopper et al, (2009), Cruz and Keefer (2010), Andrews (2011), Bunse and Fritz (2012) and Mzenzi, (2013).

The notion that accounting is important in government and in reform is neither new, nor unique. "We can consider accounting as a technique, accountability as a state of mind, and governance as a method of control and a legitimating device that are all inter-related" (Collier, 2005, P.931). Budgeting is a continual process by which governmental activities are planned, controlled, and evaluated (Freeman et al., 2006, P. 73). A sound and transparent budgeting and accounting architecture is a fundamental building block for good public sector governance. Much empirical research on PFMR has reported a number of benefits from the use of appropriate performance and control, and a greater emphasis on transparency by providing more and better information to parliaments and to the public. 
Many scholars have considered the nature of accountability and governance and their role in a variety of organisational situations, time and place (Broadbent and Guthrie, 2008). Political accountability for the government becomes managerial accountability for managers of organisations in the public service (Broadbent and Laughlin, 2003). Government accountability offers a set of practices that are claimed to be descriptive of healthy accountability relationships, namely, to set measurable goals, monitor progress, report on results, and evaluate results (Gendron et al., 2006, P.19). Governance requires such accountability through mechanisms of control and legitimation (Collier, 2005, P.930). Governance is the exercise of political, economic and administrative authority in the management of a country's affairs at all levels. It is a neutral concept comprising the complex mechanisms, processes, relationships and institutions through which citizens and groups articulate their interests. PFMR can be described as a reforming spirit aimed at increasing financial awareness in public sector decision- making and therefore an integral part of the broader public service reform Olson et al., (1998).

Researchers argued that appropriate accrual financial measurement and reporting systems must be outcomes focused and provide useful information to management and parliament for decision-making, control, performance measurement and accountability purposes. PFMR outcomes include (a) changes to financial reporting systems, cash to accrual; ( b) devolution of budgets; (c) market based costing and pricing systems; (d) a performance measurement approach; and (e) performance based (internal and external) auditing (Guthrie et al., 2005). Reform outcomes of PFMR include devolution and accountability as two concepts of decentralization: Devolution is where local government employees are responsible for administering fiscal transfers from the central level, and are accountable to local government and not to central government (Ezzamel et al., 2005, p4). Outcomes of PFMR include making the budget process more responsive to priorities; making management practices more flexible (Curristine et al., 2007).

Dynamic models are needed to document the process of reform, especially the internal processes of government (Chan, 2002). Lüder (1999) articulated several concern regarding the comparative international governmental accounting research. First, a majority of these studies were not explicitly comparative. Most papers were exploratory and did little more than describing current practices in various countries. Second, the selection of countries was usually not guided by theoretical considerations, but by individual access, knowledge and preferences. Differing in subjects, definitions and designs, their results were incomparable and could not form the basis for cross-country analysis. Third, the few cross-country studies were long on descriptions and short on a systematic analysis of international similarities and difference. Finally, there were few conceptual and explanatory studies. On the basis of these specific 
criticisms, Lüder implored scholars to conduct, for example, more of conceptual or explanatory studies, and less of exploratory or descriptive exploratory studies (Chan, 2002).

The World Bank has the leading edge knowledge and substantial global experience to assist in PFMR. Since 1984, the World Bank has assisted 74 countries in the design and implementation of PFMR. In particular, the Bank has financed 121 projects, including 86 complete and 35 active, totaling over 3.5 billion USD (as of August 2015). Actually, the total amount of funds spent or allocated for PFMR projects is around 4.5 billion USD, including the borrower cofinancing and other donor funds, among which nearly 1.5 billion USD has been spent for PFMR related information and communication technology solutions. The World Bank is a leading provider of financing and technical assistance for PFMR. However, there are two categories of developing country for which the prospects for successful PFMR may be greater. The first category is the group of emerging markets that are close to attaining the "doorstep conditions" described by NWW. By definition, such countries have an environment that is favorable to PFMR, especially the countries of central and eastern Europe that have also benefited from the additional financial "carrot" of membership of the European Union. Other countries in this category include Brazil, Chile, Korea, Mexico, Morocco, South Africa and Turkey. On the other hand, anecdotal evidence drawn from the rich experience of the IMF's technical assistance work in the field, especially in Africa. some cases, isolated progress has been madefor example, in implementing a concrete provision for which an IMF program condition has been attached - but this is quite rare. In general, the reform process has been frustratingly slow, even in narrow technical areas of the budget system (Gupta et. al., 2007)

In emerging economies, public expenditure decisions are complex, critical to macro-economic policy. Governments of emerging economies are under pressure to improve public sector performance. Thus it is crucial that decision-makers receive effective guidance for planning, decision making and control. Transnational institutions such as the World Bank and the IMF tend to promote global capitalism by forcing developing countries into market-based policies and practices (Uddin and Hopper, 2001). PFMR has been introduced in emerging economies as element of World Bank and IMF strategies for economic development in the belief that introducing more sound financial practices will contribute to economic development (Hopper and Mserembo, 2004; Hopper et.al, 2009) ${ }^{1}$.

\footnotetext{
${ }^{1}$ The World Bank elaborates on four elements of good governance (World Bank, 1989, 1992):

- Public sector management emphasizing the need for effective financial and human resource management through improved budgeting, accounting and reporting.

- Accountability in public sector, including effective accounting systems, auditing and decentralization, and generally making public officials responsible for their actions and responsive to consumers;

- A predictable legal framework with rules known in advance; a reliable and independent judiciary and law enforcement mechanisms; and
} 
Research on PSAB in emerging economies has grown somehow due to the globalization of capital markets and competition; structural adjustment programmes involving privatization and new public sector management (Hopper et al., 2009). Researchers (e.g. Hoque and Hopper 1994) addressed how the developing country context has been neglected in accounting studies and emphasize the need of paying more attention. Whittington and Mayer (2000:31) argued that 'time and place' should be taken into account when investigating managerial practices. Wilson (2003) observes that the organisation decision-making process seemed to differ between different countries and that there is little evidence of universalism. With the exceptions of the countries that are the originators or promoters of government accounting reform, much less is known about the internal processes of government decision-making in the presence of such external stimuli. Such processes might be bottom-up in the sense of starting with experimentation by local governments, as is the case of the Federal Republic of Germany (Lüder, 1998). To some extent, that is the case with the United States, though the Federal Government has made more radical changes within a decade than local governments over a much longer period of time (Chan, 2001). Furthermore, in the U.S. these policy changes were accompanied through reforming the standard-setting institutions by creating more powerful boards independent of the government, which has not taken place in Germany. In other national contexts, such as unitary states (e.g. China), one would predict the process to be a top-down one, in which the national Ministry of Finance sets government accounting policies for all levels of government.

Further, Broadbent and Guthrie, (2008) stated that the opportunity to diversify location of PFMR research and undertake comparisons should be grasped when possible as it provides the basis for contrast and comparison that facilitates our learning and allows both a transfer of good practice and prevents mistakes being repeated elsewhere. Ohenmeng (2010) examined the dangers of internationalisation and 'one-size-fits-all' in the new public sector management in Ontario, Canada, and in Ghana. Findings showed that the context in which PFMR are implemented is important. It is important to consider factors such as culture, institutional dynamism and the role of external actors in the development and implementation of reform policies. Adhikari, and Mellemvik (2011) investigated role and influence of international organisations in facilitating PFMR in developing countries. They argued the rise and fall of accrual accounting in the Nepalese central government. Findings demonstrate that the implementation of accrual accounting in the Nepalese central government has been an unsuccessful mission. Mzenzi (2013) examined accounting practices in four Tanzanian local

- Availability of information and transparency in order to enhance policy analysis, promote public debate and reduce the risk of corruption 
government authorities, to assess the accounting and budget changes. Findings indicate that the adoption and implementation of accrual accounting increased the manipulation in accounting calculations to satisfy donors rather than provide relevant accounting information of the required quality to facilitate decision-making. More recently, Jones and Caruana (2014) conducted an empirical study to assess the conduciveness of the environment surrounding PFMR of the central government of Malta. The findings indicate that the long-winded reform at the central government level of Malta may only be illusory because once the statistical reporting requirements for Eurostat were achieved, the accounting reform died. Contrary to expectations, the evidence indicates that the small size of the country may have acted as a negative factor on the PFMR process. Expertise is limited to a small cluster of officials involved in all aspects of the reform, and specialisation is barely possible. The small size of the jurisdiction then acts as a constraint, given that limited human resources can only be absorbed on prioritised issues, while not-so-important issues are placed on a 'waiting list' Caruana (2014, p.60).

The Middle East and North Africa (MENA) region has faced the challenges of good Governance and has implemented initiatives to improve the quality of governance. Public financial management is a core area that a number of MENA countries have taken measures.

For example, some countries established the basic financial management to allocate public resources in a timely fashion. Some countries also introduced performance management and multi-year framework in budgeting and tried to enhance transparency ensuring internal and external audit. Although it varies and is not easy to generalize, the MENA region still has the need to improve the quality of governance and enhance public accountability. The study of Robert, Beschel, and Mark (2012) surveys PFMR across 10 Arab countries; Algeria, the Arab countries- Republic of Egypt, Iraq, Jordan, Lebanon, Morocco, the Syrian Arab Republic, Tunisia, the West Bank and Gaza, and the Republic of Yemen - using a combination of case studies and the Public Expenditure and Financial Accountability framework. The mentioned is a set of 28 high-level indicators that measure performance against best practices in developed and developing economies. The indicators analyze performance in the six core areas of public financial management: (i) credibility of the budget; (ii) comprehensiveness and transparency; (iii) policy-based budgeting; (iv) predictability and control in budget execution; (v) accounting, recording, and reporting; and (vi) external audit. Findings indicate that PFMR has been particularly successful in MENA fall into two types: (i) efforts to improve budget transparency and classification and (ii) the reform of revenues, particularly tax and customs. Ironically, these represent two very different reforms. The first are relatively straightforward and technocratic in nature. The second often encounter fierce resistance. 
The preceding literature suggest that further research into PFMR would be valuable. In particular, there is a need for further research, case studies, covering a long -period of time to know whether and how governments perform PFMR. Accordingly, the research objective underlying this study can be expressed in the following research questions:

- What are the key drivers for PFMR in UAE?

- What are the procedures that followed in PFMR?

- What are the key challenging issues surrounding the implementation process of PFMR within the UAE context?

- What are the outcomes of PFMR?

- What are the key lessons of PFMR in UAE?

\section{Research methodology}

This study is based on conceptual and explanatory perspective with a qualitative methodological paradigm through a case study. The unit of the analysis is the MoF in UAE. The case study approach helps researchers to understand the organisational phenomenon, particularly the behaviour of the organisational actors and the internal and external environments in which it operates. Chan, Jones and Lüder (1996) voiced the need to open the "black box" of government accounting changes. One possible strategy for understanding such changes is to identify external and internal influences. There exists some preliminary evidence that foreign-aid donor organizations and nations have played a role in promoting government accounting reform in developing nations (e.g. Godfrey, Devlin and Merrouche, 1996).

Multiple sources of data have been used to answer the questions underlying this study including archival records and interviews. Interviews are conducted with key executives at the MoF; Assistant Undersecretary for Revenue and Budget, and the MoF's Manager of Budget. Within the interview transcriptions, important direct quotes were used to substantiate the findings. Important considerations in the design of the interview guide were to keep the interview to a reasonable length and focused. The interviews were carried out between March and May 2006. The interview questions encompassed questions on aspects related to the initiation phase of PFMR. Data recorded in the interview process were taped recorded and transcribed in the early stage of data analysis. The transcripts were analysed within one week after the interviews were conducted in order to obtain further information and clarification if necessary. Documentation and operating statements relating to PFMR are collected to complement the interview data including relevant documents/reports published by the MoF over the period from 2005 to 2015.

\section{Conceptual framework}

Various models have been developed in an attempt to describe and understand government reforms. In the context of PFMR, Lüder (1992) proposed a comprehensive contingency model 
of introducing accounting innovations in the public sector. Based on a comparative study of the United States, Canada, and several European countries, the model consists of four modules: stimuli, social structural variables about information users, structural variables describing the politico-administrative system, and implementation barriers. Whether a more informative accounting system is introduced depends on the specific combination of favourable and unfavourable conditions in these modules. He argued that innovation in governmental accounting is influenced by the existence of markets for users and producers of governmental accounting information. Through his contingency model, Lüder identified both contextual and behavioural variables that are potentially relevant in explaining government accounting system reform. He addressed how the attitude and behaviour of users and producers of accounting information is shaped by their respective environments.

Lüder's contingency model has served as the benchmark conceptual framework for comparative international government accounting research (Lüder, 1989, 1992, 1996). The main objectives pursued with the model were twofold: (i) it was intended to serve as a framework for empirical investigations into governmental accounting reforms and thus facilitate the comparison of research carried out by different researchers; (ii) it was meant as complex hypothesis aimed at contributing to the explanation of context influence on a special reform or innovation process and thus triggering research in confirming, falsifying and amending it (Lüder, 1994, p.3). Those innovations are the result of complex interactions of contextual variables and behavioral variables that describe the users and suppliers of government financial information. Similarly, the demand for administrative accountability and receptivity to private sector practices may influence the way the bureaucracy views the information it provides to the legislature and the public at large. In other words, societal, political and administrative structural variables are hypothesized to have significant effects on the expectations and behavior of those who demand and supply government financial information. When a particular configuration of these variables creates favorable conditions sufficient to overcome the implementation barriers, innovations are likely to occur.

The model has been refined by many researchers and applied in different national contexts (e.g. Chan, 1994; Chan, 1995; Jaruga and Nowak, 1996, Godfrey, Devlin and Merrouche, 1996; ElBatanoni and Jones, 1996; Godfrey, Merrouche and Devlin, 1999; Godfrey, et al., 2000; Christensen 2002; Ouda, 2004; Saleh, 2006; 2007; Harun and Robinson, 2010; Ouda, 2011). Godfrey et al., (1996) modified the contingency model by identifying factors that relate specifically to developing countries such as the influence of international funding organisations and donor agencies. The demands of international organisations and donor agencies in providing assistance can directly or indirectly stimulate the change process (Godfrey et al., 1996; Hood 1995). The diffusion-contingency model of government accounting for application in developing countries was developed by Godfrey et al (1996). They argued that developing 
countries might change their accounting system not only to meet international funding agencies' requirements but also to improve the country's international reputation. Their model incorporates the diffusion of government accounting into two stages: initiation stage and implementation stage. The initiation stage relates to the impact of internal and external stimuli for change. The implementation stage explains the process of change including barriers to change.

Ouda (2011) proposed a prescriptive model of the transition to accrual accounting in the central government. The main objective of the prescriptive model is to present a comprehensive transition framework that aims at explaining the whole reform process including all relevant factors and seeking to overcome the shortcomings of the earlier developed governmental accounting innovation models (e.g., contingency model) by focusing not only on the contextual and behavioral variables and on creating a climate fit for the accounting reform process, but also on the content, technical and capacity variables. Ouda's prescriptive model consists of three phases: reform decision-making phase, transition phase, and post-transition phase, this is in addition to final result and overcoming the transition barriers (Ouda, 2011). Ouda's prescriptive model aims to create a clear transition framework identifying the requirements of a reform that not only initiates but also successfully completes an accounting reform process: "how to enter the tunnel and reach the end of it" (Ouda, 2011, p.67). However, an explanatory model may be more applicable in a study that attempts to identify the how and why of governmental accounting reforms. Accounting reforms are initiated but it may not be the intention of the actors themselves to actually reach the end of the tunnel (Ouda, 2011).

The conceptual framework underlying this study is rooted in the contingency theory to explain the occurrence of PFMR in UAE as illustrated in Figure (1). The model is rooted on Lüder (2002, p.18); Godfrey, Devlin \& Merrouche (2001, p. 282) Ouda (2011, p.72); Jones and Caruana, (2014, p.77), The rationale underlying the modified model refer to the fact that PFMR process can be better understood by integrating clusters of the explanatory factors and the implementation factors in one conceptual framework. Explanatory factors address the variables related to the influence of contextual factors on PFMR. Implementation factors specify the prerequisite modules for successful implementation of the transition processes. The proposed model consists of two clusters of contextual variables (stimuli and institutional arrangements), three clusters of behavioural variables (reform drivers, political reform promoters and stakeholders) and two clusters of instrumental variables (reform concept and implementation strategy). 
Figure (1): Conceptual framework: PFMSR process in UAE.

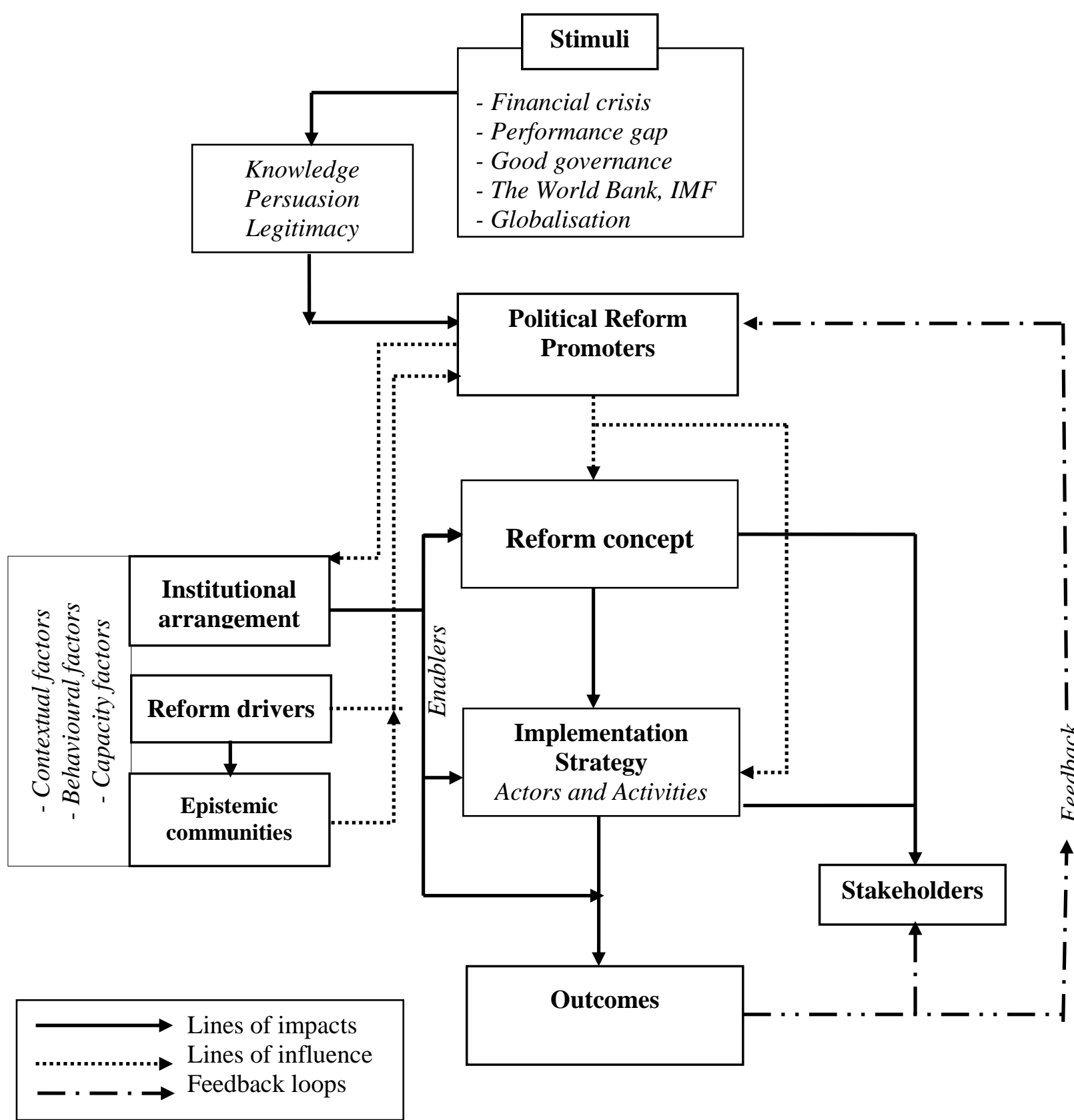

Source: The author, the adapted model based on Jones and Caruana, (2014, p.77), Ouda (2011, p.72); Lüder (2002, p.18). 


\section{PFMR process in UAE}

\section{Background: The UAE:}

The UAE is a federation of seven emirates, and was established on $2^{\text {nd }}$ December, $1971^{2}$. Sheikh Zayed, ruler of Abu Dhabi and the first President of the UAE, oversaw the development of the Emirates and steered oil revenues into healthcare, education and infrastructure. In 2013, the UAE's population was 9.2 million, of which 1.4 million are Emirati citizens and 7.8 million are expatriates. The UAE's economy is the most diversified in the Gulf Cooperation Council, with its most populous city of Dubai is an important global city and an international aviation hub. Nevertheless, the country remains principally reliant on its export of petroleum and natural gas The UAE's per capita GDP is on par with those of leading West European nations. For more than three decades, oil and global finance drove the UAE's economy. The UAE's oil reserves are the seventh-largest in the world, while its natural gas reserves are the world's seventeenthlargest. In 2008-2009, the confluence of falling oil prices, collapsing real estate prices, and the international banking crisis hit the UAE especially hard. The UAE essentially avoided the "Arab Spring" unrest seen elsewhere in the Middle East in 2010-11 and in an effort to stem potential unrest, the government announced a multi-year, \$1.6-billion infrastructure investment plan for the poorer northern emirates and aggressively pursued advocates of political reform. The UAE in recent years has played a vital role in regional affairs

Recent socioeconomic and political events have triggered a global interest in government systems and practices. Structurally, UAE is a small country, decentralized emirates where local government takes responsibilities of many functions. Each emirate retains considerable autonomy over economic and financial affairs. The UAE economy is somehow strong, buoyed by high oil prices. In the 2012 United Nations E-Government Index, the UAE improved its overall from 49th in 2010 to 28th, to become ranked first amongst Arab countries, second amongst peers in Western Asia, and fifth in Asia ${ }^{3}$.The UAE's position in the e-service index moved from 99th to 7th and in the e-participation index, its position improved from 86th to 6th.This was achieved by conducting an in-depth review of whole of government service delivery to provide a more detailed understanding of the factors for improvement in egovernment and incorporating a strategic plan into the "UAE Vision for 2021". The UN lists the UAE as one of the few countries in the world that comes closest to a "one-stop shop" of government information and offerings. A "platform" approach is used to provide an interface with common tools and functionalities for local service delivery actors that can be customized

\footnotetext{
${ }^{2}$ In 1971, six of these states - Abu Dhabi, 'Ajman, Al Fujayrah, Ash Shariqah, Dubayy, and Umm al Qaywayn - merged to form the United Arab Emirates (UAE). They were joined in 1972 by Ra's al Khaymah.

${ }^{3}$ International Monetary Fund, Strategies for Fiscal Consolidation in the Post-Crisis World (IMF: IMF Multimedia Services Division 2010)
} 
to meet the needs of their clients. The UAE has implemented a number of leading practices designed to radically improve the efficiency of government through better service delivery. The government strategy 2011-2013 lays the foundations to achieve the UAE Vision 2021.It forms the basis upon which the federal entities develop their strategic and operational plans, and consists of seven general principles, seven strategic priorities, and seven strategic enablers. The seven general principles steer the work of the UAE Government and apply across all strategic priorities and strategic enablers. The seven strategic priorities are the themes that define the priorities of the UAE Government over three years.

The corporate governance culture in the UAE is relatively weak and lacks transparency. Henceforward, The UAE Government addressed the need for a good institutional governance by the development of governance systems in ministries, authorities, and federal institutions throughout the federal government. The government focuses on decentralization and granting government entities more authority and flexibility with a view to enhancing managerial efficiency. This is towards enhancing the overall governance framework within the federal government by optimizing government institutional set-up, improving internal governance of federal entities, and fostering a culture of accountability.

The UAE Government has a comprehensive training and development system. The system has set out clear roles and responsibilities for the Federal Authority for Government Human Resources, HR departments within organizations, leaders, line managers and employees. Core and leadership competency skills are well defined and a robust performance management system is in place. Core skills include strategic, people, financial, operational and program, knowledge and communication management. The training and development system has a clear framework for defining organizational and individual development needs and activities. The Government Leadership Programme aims to develop a pool of talent for the UAE Government from which future visionary government leaders who have the required ability, knowledge, skills and experience can be drawn. The program involves a combination of training courses, seminars and workshops, case study scenarios, study visits, networking events, mentoring/coaching, personal development planning, public sector expert speakers, job development assignments and online development.

\subsection{Stimuli}

PFMR in UAE has been instigated as part of the overall NPM framework undertaken in 2004, with the intention of improving economy, efficiency and effectiveness of government operations. PFMR in UAE was a key requirement for policy formulation, management and control of resources and effective audit towards the four pillars underlying NPM. The need for PFMR arises from the fact the cash accounting system is not an informative accounting system for strategic decisions making. The conventional cash accounting system can't demonstrate the 
responsibility/accountability of government for the use of scarce resources. Governments need an accrual budgeting system so that actual results can be measured against plans and budget (Ouda, 2004). Prior to PFMR, the MoF was not able to provide reliable information for performance measurements of the government and their impact on the economy. This deficiency refers to the limitations of cash accounting and incremental budgeting system used by the UAE federal government. This approach to budgeting focuses on inputs does not provide decision-makers with the information necessary to make informed decisions about expenditure priorities and to use the budget as a tool for getting value for money. Before 2008, a government performance management system has not been in place in UAE. Therefore, the $2008-2010$ plan of the UAE federal government addressed the evaluation of the governmental sector performance as one of the targets of the mentioned plan.

Globalization, professional organisations (e.g. The World Bank, IMF), financial crisis, problematic financial situation, performance gap have influence on PFMR. These characteristics have created favourable environment for the development of a governmental accounting system in UAE. Fiscal stress enforced many governments in both advanced and emerging economies to focus on accountability and good governance mechanisms to achieve greater efficiency, effectiveness. During 2004 and 2005, there were significant increases in the volume of shares traded on Dubai Financial Market and the share prices of many companies. However, through 2006 the bubble burst and share values dropped by around 60\%, along with similar decreases in most Gulf stock markets. GDP growth fell from a high of 13\% in 2006 to a decline of $2.7 \%$ in 2009, mainly due to the collapse of the real estate sector in Dubai.

The direct result has been an internal shift in power relations among the federation's constituent emirates, with Abu Dhabi now exerting more central control over decision-making than before. Financial crisis in the UAE acts as another stimulus to accelerate the process of economic reforms including the implementation of NPM one element of which was PFM. The 2003-08 oil price boom led to large fiscal and external balance surpluses, buoyant economic activity, rising consumer and investor confidence in the UAE. Abundant liquidity fuelled credit growth, inflation, and asset price increases. During this period, real annual average credit growth of the UAE banks. Speculative investments contributed to marked increases in real estate prices. These developments took place notwithstanding the fact that UAE implemented several measures of macro prudential nature to limit credit growth. While most of this credit growth was financed by domestic deposits, banks' foreign liabilities increased, partly related to banks' issuance of foreign-currency denominated medium-term notes. However, banks also used short-term speculative foreign deposits to finance their lending, exacerbating maturity mismatches and creating a refinancing risk on their balance sheets. On the corporate sector side, the boom was associated with a rise in leverage, increasing the sector's vulnerability to funding availability and cost. The credit and asset price boom came to an abrupt end as the global 
financial crisis hit the UAE in late 2008. All of these indications point to stimuli as a potentially important driver of PFMR.

\subsection{Political reform promoters}

The UAE government has accelerated the development and implementation of NPM through a number of measures intended to strengthen the legislation framework and improve oversight of the use of public resources. A key priority for the UAE federal government is to achieve significant a new era of public administration. The changes envisioned and undertaken by the UAE leadership represent an indigenous initiative reflecting the need to transform the country's traditional political heritage - based on consensus, the primacy of the consultative process and gradual social change - into a more modern system that takes into account the rapid socioeconomic advances made since the establishment of the federation.

The government strategy (2007) was based upon the national programme unveiled by the president of UAE in December 2005. It was based on extensive consultation between the federal ministries, as well as other bodies. The strategy was launched by the prime minister in 2007;

"It sets the foundations for a new era of public administration. The changing times and the nature of the challenges prompt us to think in a different way and to adopt international best practices in the area of public administration. This strategy unifies efforts within a strategic framework with clear objectives, based on detailed studies (and) ...clearly identifies and integrates federal and local efforts".

The role of the MoF is to enable, support and drive an integrated and collaborative approach with line ministries towards PFMR. This is due the commitment of the MoF to the government strategy, to secure continuous improvements in performance measurement, transparency, accountability and governance. PFMR has been among early stages of government reforms and it is considered as an important condition and prerequisite for the success of other subsequent public sector reforms under the NPM movement.

PFMR has been viewed by the federal government as crucial element of economic policy reform program to achieve value for money in public money spending and promote control, accountability and governance. "Better for less", providing "real value-for-money" and commitment to excellence in administration and service delivery are key reform concepts inherent in the government's strategy. UNDP consultants, professional accounting and auditing bodies are entrusted with the task of drafting and codifying the basic principles of PFMR.

\subsection{Implementation strategy: 4.3.1. Federal budget law statute}

Financial legislation expressed in accounting procedure and report content regularly issued by the MoF. Such new rules create new procedures. Thus, such financial legislation is favourable to $\mathrm{BSABR}$. The legislation empowers the $\mathrm{MoF}$ to issue guidance regarding accounting 
standards with a legal notice that does not require approval from the UAE cabinet ministers. It is normally expected that the implementation of a new accounting system is easier and less expensive in a smaller jurisdiction (see Lüder, 1992:118). The implementation strategy of PFMR was initiated by the enactment of the new organic budget law in 2005, the new budget law was inherent in the $2008-2010$ plan of the UAE federal government. The previous budget law embedded characteristics of traditional inadequate cash accounting and incremental budgeting systems. The new organic law amending the federal law No. 14 of 1973 on the rules of the preparation of the state budget and final account implemented from January 2005. Primary objective of this new law is to improve public expenditure management framework oriented towards achieving results and raising performance. In August 2003, for the first timeas experimentation- the UAE federal budgets was prepared using traditional budget system and performance based budgeting system.

"performance based budgeting system ties policy-making with resource realities, improving the allocation of funds to strategic priorities among and within economic and social sectors. It provides managers with more autonomy and encourages professionalism, initiative and innovation"

(Assistant Undersecretary for Revenue and Budget at the MoF)

\subsubsection{New chart for the federal accounts and transition process towards accrual accounting}

Ten budget categories in the new chart of accounts New chart for the federal accounts was developed in $2006^{4}$. The transition from cash-based accounting to modified accrual (January 2005) and then to accrual-based accounting system as expected from January (2007). Such transition has changed the traditional role of accounting to one that is more focused on accountability, output, and performance measurement.

“.....We are aiming to gain international recognition for our accounting systems as well as strengthen our management reporting, resulting in an overall improvement in planning and control, while providing decision makers with crucial financial data".

(Assistant Undersecretary for Revenue and Budget at the MoF)

\subsubsection{Financial procedures guidelines and training programmes}

The lack of certain general skills in the accounting field may create implementation barriers which cannot be eliminated in the short term and which may in certain circumstances mean that attempts to introduce more informative accounting will fail. Financial procedures guidelines for the federal government and draft for the law of public debt. Employees of the ministries and

\footnotetext{
${ }^{4}$ Ten budget categories in the new chart of accounts: (1) compensation of employees; (2) use of goods and services; (3) interests;(4) subsidies; (5) grants; (6) social benefits; (7) other expenditures; (8) cash expenditure transactions involving purchase of non-financial assets; (9) cash expenditure transactions involving financial assets; and (10) cash expenditure transactions involving liabilities.
} 
federal authorities (more than 1,200) have received training regarding PFMR process including technical guidelines regarding the implementation of performance based budgeting. Accordingly, the training of administrative, especially accounting staff, and the recruitment of financial controllers and auditors are factors that influence the basic attitudes (i.e., readiness to accept change) of the information producers. The MoF organized on a permanent and demanddriven basis, technical courses and workshops for the technical staff of ministries and other federal agencies regarding the implementation of PFMR

"The ministry has launched training programmes in the area of PFMR for the technical staff of ministries and other federal agencies. More work has been done in 2004 but so far more than 1,200 employees have been trained on PFMR. .......The 2005 budget was based on performance based budgeting system......... The ministry has also published technical guidelines regarding the implementation of new budgeting system".

(MoF 's Manager of Budget)

\subsubsection{Zero based budgeting: Medium-term expenditure and budget framework}

In accordance with the Federal Law No 23 (2005) which is related to strategic and operational plans of ministries, the MOF developed performance indicators towards decentralization, transparency and accountability. In 2008, the UAE Cabinet issued resolution regarding the development of UAE's financial system and the application of the medium-term zero budget 2011 to 2013. A draft of the budget was discussed in April 2010, before being presented in its final form in September (2010) and applied at the beginning of 2011. Zero based budgeting involves a triennial review process where departments start from a blank sheet of paper and build a budget from the bottom-up. Budgeting teams are then tasked to define activities contributing to agreed objectives that will exist over a budgeting time horizon of three years, and justify activities and their associated costs by providing a detailed cost analysis. Teams prioritize the activities based on a cost-benefit analysis and rank them relative to their contribution to strategic objectives. Zero-based budgeting system is viewed by the federal government as mechanism for a better understanding of the needs of the society and to achieving transparency in government activities. It was viewed as effective mechanism to maintain integration among the UAE's strategic planning, fiscal policy and expenditure control. However, successful implementation depends on the adoption of accountability and appropriate performance indicators.

The MoF also set up a team to communicate with ministries and federal bodies regarding the implementation of Zero-based budgeting system by 2008. Thus, the transition process creates new roles/responsibilities for public sector executives including reformulating their vision, mission and strategic goals. Prior to 2005, the country had experienced a spate of budget deficits stretching back throughout 1982-2004. The UAE announced its third consecutive Zero deficit budget in 2010 justifying its move toward performance based budget strategy. The UAE 
minister of state for financial and industrial affairs stated at the announcement of the budget in 2010.

"Maintaining a Zero-sum budget was the reason for implementing the performance and programme-based budget as a basis, in addition to the new budget law issued last year, which stipulates the necessity of drawing up a balanced budget. A balanced budget is a means rather than an end to serve the budget programme and to enable the different sectors to achieve their goals."

Incremental budgeting assumes a stable environment where current activities persist at roughly same cost in future years. It assumes that current budget levels are well understood and therefore do not require bottom-up justification making budgeting a routine process. Zero based 3-year budget 2011-2013 was developed in the first half of 2010, incorporating inputs from 2011-2013 strategic plans. The framework for the UAE federal budgeting and budget execution (2013) has major elements that all comply with international best practices to enhance transparency and efficiency:

- Definition of sectoral spending targets

- Alignment of budget with government strategy through program budgeting and performance monitoring

- Seamless integration of annual budgets in three-year budget cycles

- Application of zero-based budgeting

During the budgeting process, the federal strategy is translated into a program structure that consists of high-level strategic objectives and directly implementable programs and activities. The strategic plan (2011-2013) deals with seven priorities: (1) reaching or assuring a cohesive society while preserving the national identity, (2) creating a first- rate education system, (3) ensuring world-class healthcare, (4) maintaining a competitive knowledge-based economy, (5) ensuring the presence of a sound transparent and fair judiciary, (6) sustainable environmental and infrastructure polices, and (7) protecting the country's strong global standing. In accordance with the mentioned strategic priorities, the 2011 federal budget, approved in November 2010. For example, $46 \%$ of its total is allocated to social development issues, including education, health care, pensions and social assistance. Sufficient resources are allocated to each layer of the program structure. The effectiveness of spending in this program budget is monitored, and the performance will be used as an input for future budgeting processes. The UAE federal government follows a three-year budgeting cycle. The three-year 
period is synchronised with the three-year federal strategy. Within the three-year budget, separate allocations are made for each year.

When building three-year budgets, ministries/autonomous agencies must apply a process of zero-based budgeting. Zero-based budgeting contains three steps: bottom-up cost allocation without prior assumptions. The zero-based budgeting exercise is comprehensive and covers all areas of spending. Zero based budgeting is useful under specific circumstances;

- Rapidly growing GDP and need for large-scale infrastructure development

- Low historic transparency of budgets

- Clear differences between original budget requests from ministries and ultimately approved budgets

These conditions fit well with the UAE as the GDP increases from \$222.11 billion in 2006 to $\$ 370.29$ billion in 2015 as shown in Table (1). The large accumulated budget surpluses have resulted in a wide-ranging economic development program, with particular focus on infrastructure, health care and educational services.

Table (1): UAE GDP: US \$ Billion

\begin{tabular}{|c|c|c|c|c|c|c|c|c|c|}
\hline 2006 & 2007 & 2008 & 2009 & 2010 & 2011 & 2012 & 2013 & 2014 & 2015 \\
\hline 222.11 & 257.92 & 315.5 & 253.5 & 286 & 347.5 & 372.3 & 402.3 & 399.45 & 370.29 \\
\hline
\end{tabular}

Source: World Bank Group

Consolidated public debt remains low and stable at $26 \%$ of GDP. The government has also made some progress in strengthening its economic institutions. It has established a debt management office, launched a public expenditure review and set up a midterm budget framework. However, the availability of macroeconomic data and disclosure of the government's external assets is relatively poor.

The 2015 federal budget, which priorities social spending, target a 6.5\% increase in expenditure. Public expenditure on social welfare and development, including education will account half of total spending. Strong current and capital expenditure will continue. The objective of a medium-term budget is the allocation of resources for the nation's strategic priorities and to ensure that these allocations are consistent with overall fiscal objectives. This gives some degree of predictability to spending federal authorities at the same time ensuring overall fiscal discipline. The medium-term budget framework is the base type of the mediumterm expenditure framework.

\subsubsection{Establishment of accountability authority}

The establishment of the Abu Dhabi Accountability Authority in January 2009 is an important step towards strengthening PFMR. The aim of the new accountability authority is not only to 
ensure compliance with rules and regulations, but also to promote the principles of accountability, transparency and governance. Further, in 2010, the government implements an updated code of corporate governance in an attempt to introduce internationally accepted corporate governance principles into the UAE.

\subsubsection{Organisational restructuring}

The transition process offers the MoF considerable degree of autonomy with regard to policy implementation and changes in its strategy, process and structure. The new organizational hierarchy/structure of the MoF is presented in Figure (2).

At the micro level, it is expected that PFMR process will allow government ministries and autonomous agencies the ability to exercise greater discipline in setting and enforcing budget constraints. Also, it is expected to foster the development of accountancy mechanisms that allow public sector managers the ability to assume more authority in setting how outputs and outcomes will be achieved.

PFMR process creates organisational change including roles and responsibilities for the MoF and other executives in line ministries. The MoF has a stronger incentive to show that MoF fulfilled interest groups requirements including the public and the federal government regarding the soundness of the budgetary management. Particularly, the use of budgetary resources over the strategic priorities of the federal government in the UAE. PFMR creates new role/responsibility for public sector executives in achieving results, ensuring efficient use of the available resources, ensuring impartial implementation of law and rules, and providing expertise and technical knowledge to interest groups surrounding it environment. The new roles and responsibilities may create institutional pressures.

"Each ministry must specify the number of programs they need. Each program has inputs and outputs which should achieve in the specific period of time. They have to identify efficiency indicators to compare inputs and outputs, and effectiveness indictors to compare outputs with outcomes"

(MoF 's Manager of Budget)

"The UAE is implementing a modern organic Budget Law along with performance-based budgeting to achieve better disclosure and greater transparency, and linking spending with outcomes and measurable results to provide a dynamic planning tool for a period of three years."

(The UAE Minister of Finance and Industry, 2010) 
Figure (2) MoF: New Organisation Chart

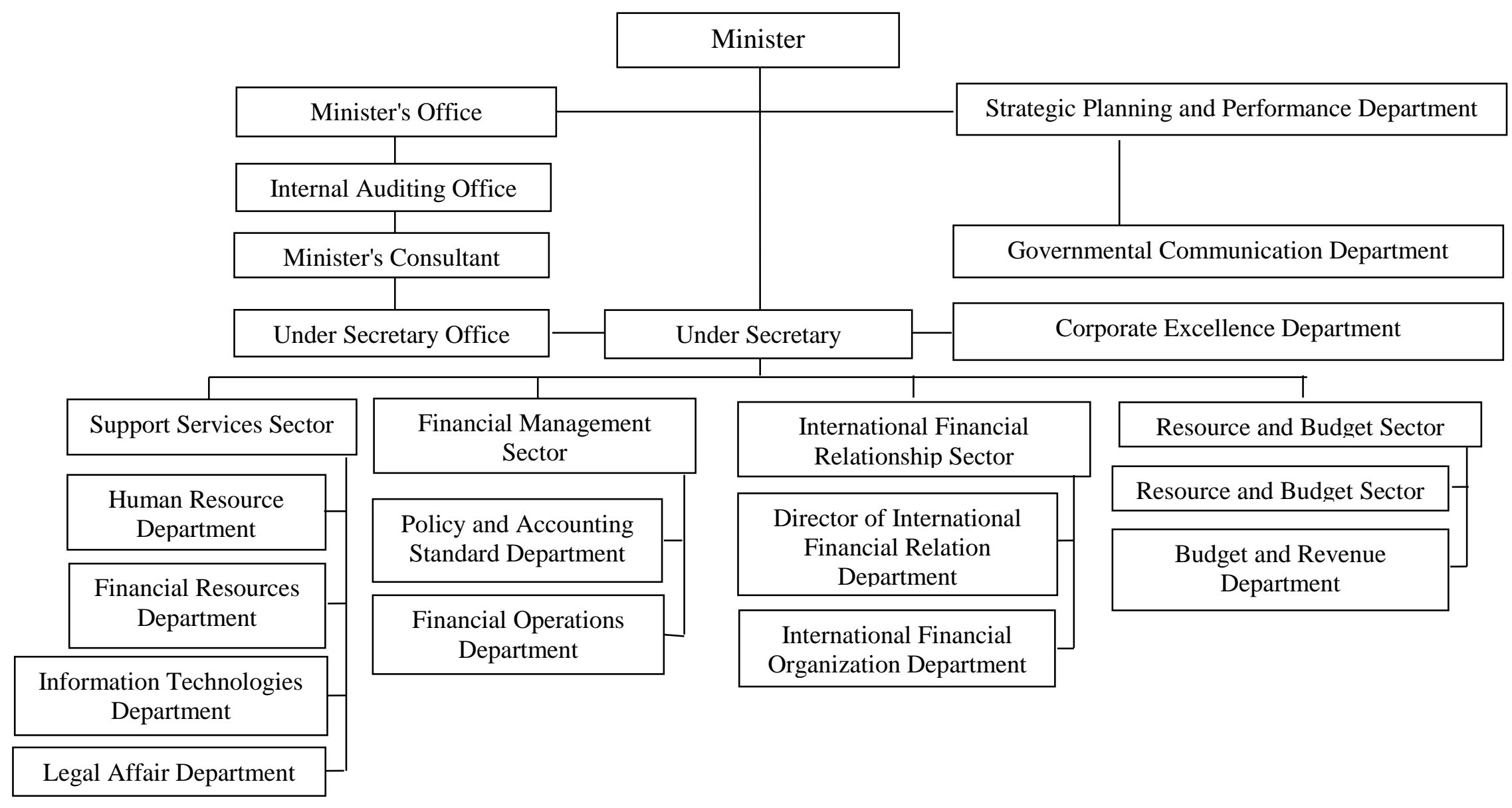

Source: MoF, UAE. 
PFMR process creates organisational change within the MoF including reformulating the MoF's strategy, processes and organisational structure. New departments have been established within the MoF through the transition process (e.g. The Budget Department and the Financial Operations Department at the MoF Department for Economic and Financial Analysis, Macro-Fiscal Unit, Public Debt Management Office, Federal Authority For Revenues, And Treasury Management). More recently, as part of UAE's plan to implement the Federal Tax System, and establish the Federal Tax Authority, the MoF announces its need for recruiting qualified candidates for some vacancies (this was noticed by December 2016) $)^{5}$. Also, the MoF expand the human resources to fit with the reform requirements. The adoption of new practices and procedures is aimed at increasing organisation's legitimacy and survival prospects (Meyer and Rowan, 1991).

\subsubsection{Information technology}

Reliance on information technology through the implementation processes of PSAB reform. Oracle system was used by the MoF to assist the federal government to manage and control its activities including implementation and management of the budget. In line with the principles of transparency, openness, cooperation and sharing. The MoF has adopted the open data concept. The MoF provides many files and documents through its website that includes content that can be shared and republished to increase the level of public and specialised knowledge of its practices. The UAE realises the importance of making data and information available for government and private sectors as it allows citizens and residents access to whatever they need and can support their participation in the development process. This falls under the philosophy of understanding community needs and achieving the global competitiveness requirements. In this context, the UAE launched several initiatives related to information and services in the fields of knowledge, publishing and introducing facts, statistics and data 6 .

The World Bank is a leading provider of financing and technical assistance for PFMR. The World Bank provides technical support to the MoF regarding PFMR. The Budget Department and the Financial Operations Department at the MoF, after obtaining the necessary approvals, will support ministries and federal entities in the preparation of budgets

\footnotetext{
5 The listed vacancies include Compliance and Enforcement Director, Senior Tax Auditor, Tax Auditor, Tax Analyst, Senior Compliance Auditor, Compliance Analyst, Contact Centre Head, Contact Centre Agent, Finance Director, Budget \& Planning Accountant, Legal Counsel, Corporate Development Director, Internal Audit Director ... etc.

${ }^{6}$ These efforts culminated in achieving first place in the MEN A region and 26th globally in the Corruption Perceptions Index 2013 issued by Transparency International. The index includes measures for the levels of disclosure, obligation to disclose, and the publishing of, information and statistics
} 
by identifying budget caps, approved strategic objectives and revenue forecast, as well as modifying and developing new items, making transfers between budget items and expenditures as needed, issuing periodic financial reports to follow-up on budget execution, and preparing and submitting the consolidated final account of the budget. These services also include approving additional appropriations requested by federal entities for their budgets:

- Developing and Approving Budget Drafts of Federal Entities: This is a procedural process that is carried out through communicating with ministries and federal entities on an annual basis, for the purpose of issuing the general federal budget, including the budgets of ministries and autonomous federal agencies. This process provides the Financial and Economic Committee with an initial conceptual framework for the budget draft

- Approving Additional Appropriations in the Budget: This service deals with the provision of additional appropriations requested by a government entity to meet new requirements or finance new plans and programs. The service requires obtaining the approval of the Financial and Economic Committee and the Cabinet.

- Modifying budget programe structure: This service allows for the modification of items and programme structures of the budget, as well as the development of new ones according to work needs and requirements, which means developing items in the budget classification manual. It is carried out once necessary approvals are obtained to ensure effective and accurate spending of funds.

- Transferring allocations between chapters and programmes: This service deals with considering, approving and submitting requests made by ministries and federal entities to make transfers - as needed - between budget items and expenditures for the concerned entities.

- Issuing A Periodic Financial Report to Follow-up on UAE Budget Execution: This service deals with issuance of a periodic/monthly financial report with a view to following-up on the performance of federal entities, to provide guidance and to ensure accuracy and transparency of the procedures of executing the approved budgets.

- Preparing and submitting the Consolidated Final Account of the Budget to the Federal Government: This service involves compiling and auditing spreadsheets of the Final Account of the federal budget (budgets of ministries and authorities listed in the general budget) against the Trial Balance to prepare the draft law of approving the consolidated Final Account for the federal government and following up the implementation of the budget's annual plan. 


\section{5- Conclusions}

This paper has explored the influence of contextual factors on PFMR in the UAE. The duration for PFMR process is not the same for all countries. In the UAE, the period under review (2003-2016) has witnessed a strategic change in government activities. The post2009 period has witnessed a new vision for the UAE government that promote considerable change that often represents a major departure from traditional norms and practice. New organizations have been created and significant amendments have been made to the regulatory framework.

The importance of PFMR has been recognized and acknowledged and the transition process led by the MoF. Finding of this study show that PFMR process can't be viewed as isolated initiative, rather, as part of a set of broader NPM reforms to strengthen public accountability for performance. The transition process creates major organisational changes; strategy, structure (new rules and roles), culture (core values about organisational vision, mission, and objectives), Benchmarks and milestones have been set in the accompanying monitoring matrix, though in practice delays have typically occurred in the implementation of reforms. The findings of this study confirm the view of earlier research findings (e.g. Hopper et.al, 2009; Ouda, 2004 and 2011: Robert Beschel and Mark, 2012)

Since 2004, there has been an extremely large reform agenda touching on almost all aspects of the PFMR process.

The period under study has witnessed accomplishing the following issues with regard to the implementation of PFMR:

- New budget law

- New chart for the federal accounts and transition process towards accrual accounting

- New classification of the budget

- Multiyear perspective in fiscal planning, expenditure policy, and budgeting,

- Programs and sub-programs framework

- A move to performance or results based budgeting

- Zero based budgeting

- Predict the availability of funds for commitment of expenditures

- Recording and management of cash balances

- Effective payroll controls

- Publishing and introducing facts, statistics and data

- Establishment of accountability authority

- The establishment of the Abu Dhabi Accountability Authority in January 2009 
- Reliance on information communication technology assists the MoF to support ministries and federal entities in the preparation of budgets by identifying budget caps, approved strategic objectives and revenue forecast, as well as modifying and developing new items, making transfers between budget items and expenditures as needed, issuing periodic financial reports to follow-up on budget execution, and preparing and submitting the consolidated final account of the budget. These services also include approving additional appropriations requested by federal entities for their budgets.

- Structuration within the MoF including reformulating its strategy (new vision, mission and objectives), processes and structure (e.g. The Budget Department and the Financial Operations Department at the MoF Department for Economic and Financial Analysis, Macro-Fiscal Unit, Public Debt Management Office, Federal Authority for Revenues, And Treasury Management

- Plan to implement the Federal Tax System, and establish the Federal Tax Authority).

- Limited public access to key fiscal information

However, challenges ahead facing the MoF are summarised as follows:

- Comprehensiveness of information included in budget documentation.

- Extent of unreported government operations

- Transparency of intergovernmental fiscal relations

- Oversight of aggregate fiscal risk from other public sector entities

- Orderliness and participation in the annual budget process

- Competition, value for money, and controls in procurement

- Effectiveness of internal controls for no salary expenditure

- Effectiveness of internal audit

- Regularity of accounts reconciliation

- External audit reports

- Accurate indicators for performance measurement

- Effective external and international pre-decision control mechanisms regarding the capital expenditure

- Well-designed programs to provide the essential linkages between policy, funding, and activities. Further. program and sub-program structures need to be reviewed comprehensively over several years to provide a more accurate and informed framework for expenditure policies, strategies and performance measurement.

- Building the required skills and capacity in MOF and other agencies

- Effective macro-economic policies analysis and forecasting.

- Prioritization and reallocation to align budget with the available resources. 
- High level of transparency and accountability regarding the government's budgetary objectives and intentions for social and economic development.

PSAB reforms embraces processes, structures, strong leadership, a long-term commitment and momentum, effective partnership working, a combination of economic, social, political and technological factors. The ability to translate strategic priorities into the federal budget, and to ensure conformity of actual expenditures with the federal budget, depends to a large extent on a wide range of basic supporting subsystems, from revenue and macroeconomic forecasting to auditing and performance/policy evaluation. Failure of any system may negatively affect other subsystems and may undermine the effectiveness of the whole public sector budgeting reform in UAE.

The above concluding remarks provide implications/lessons for other finance ministries considering PFMR. The technical change is being achieved, but it is too early to say whether or not the change will be successful. Therefore, successful implantation of PFMR towards transparency, accountability and governance in the UAE can't be predicted at this stage as the journey towards PFMR is still ongoing, and not arrive its distention yet.

Finally, the findings of this study should be understood in the economic, social and historical context of the UAE. Given the narrow scope of this paper, a single case study, the findings are used for theorisation rather than offering generalisable results. Crucial themes for future research including how public sector executives employ effective independent measures of outcomes. The impact of basic supporting subsystems in translating strategic priorities and integrating them into the federal budget.

\section{Acknowledgement}

The author is grateful to Professor Trevor Hopper (University of Sussex, UK) for comments on early drafts of this paper, and Dr. Khaled Aljifri (United Arab Emirates University, UAE) for contributions all throughout the interviews stage with the MoF. I would also like to thank the MoF staff who participated in this study. 


\section{References}

Adhikari, P., and Mellemvik, F (2011), "The rise and fall of accruals: A case of Nepalese central government', Accounting in Emerging Economies, 1, 2, pp. 123 - 143.

Armenakis, A. A., \& Bedeian, A. G., 1999, "Organizational Change: Review of theory and research in the 1990's", Journal of Management, vol. 25, No. 3, pp. 293-315

Alam, M. and Holloway, D. (2012), Performance management in Australia's public mental health service: A state based perspective. Australian Journal of Public Administration, 71, 1, pp. 20 -32.

Andrews, M. (2011), Does change space influence public sector management project success? World Bank.

Ball, A., and Craig, R. (2010), "Using neo- institutionalism to advance social and environmental accounting?", Critical Perspectives on Accounting, 21, 4, pp. 283- 29.

Boex, J. (2003), “The incidence of local government allocations in Tanzania”, Public Administration and Development, 23, 5, pp. 381-391.

Bracci, E. and Llewellyn, S. (2012), Accounting and accountability in an Italian social care provider: Contrasting people-changing with people-processing approaches. Accounting, Auditing \& Accountability Journal, 25, 5, pp.806-834

Broadbent, J. and Guthrie, J. (2008), "Public sector to public services: 20 years of "contextual" accounting research", Accounting, Auditing \& Accountability Journal, 21, 2, pp.129 - 169.

Broadbent, J. and Laughlin, R. (2005), "The role of PFI in the UK Government's modernisation agenda", Financial Accountability \& Management, 21, 1, pp.75-97.

Broadbent, J. and J. Guthrie (1992), "Changes in the public sector: A review of recent "alternative" accounting research", Accounting, Auditing \& Accountability Journal, 5, 2, pp. 3-31.

Bunse, S., and Fritz, V., (2012), "Making public sector reforms work; Political and economic contexts, incentives, and strategies" Policy Research Working Paper, 6174, The World Bank.

Chalu, H. (2010), 'Dimensions and determinants of accounting information systems performance in Local Government Authorities in Tanzania', PhD thesis, University of Dar es Salaam.

Chan, J. L. (2002), Comparative International Government Accounting Research (CIGAR) methodology: issues and strategy, in Montesinos, V. and Vela, J. M. (eds.), Innovations in Governmental Accounting, Kluwer Academic Publishers, 23-29.

Chan, J.L., Jones, R.H., and K.G. Lüder (1996): "Modeling governmental accounting innovations: An assessment and future research directions", Research in governmental and nonprofit accounting, 9, pp. 1-19

Chevauchez, B. (2007), "Public Management Reform in France", in Performance Budgeting, ed. by M. Robinson (New York: Palgrave-Macmillan).

Collier, P. M. (2005), "Governance and the quasi-public organisation: a case study of social housing", Critical Perspectives on Accounting 16, pp.929-949

Connolly, C., Reeves, E., and Wall, A. (2009), "Isomorphism: An explanation for the popularity of public-private partnerships?”, The Irish Accounting Review, 16, 1, pp. 1- 19.

Curristine, T. Lonti, Z. and Joumard, I. (2007), "Improving Public Sector Efficiency: Challenges and Opportunities", OECD Journal on Budgeting, 7,1, pp.1-41

El-Batanoni, K. and Jones, R.H., (1996), “Governmental Accounting in Sudan”. Research in Governmental Nonprofit Accounting, 9, pp.209-217.

Ezzamel, M., Hyndman, N., Johnsen, A., Lapsley, I. and Pallot, J. (2005), “Conflict and Rationality: Accounting in Northern Ireland's Devolved Assembly", Financial Accountability \& Management, 21,1, pp.33-55.

Freeman, R. J., Shoulders, C. D., Allison, G. (2006), Governmental and Nonprofit Accounting: Theory and Practice, 8th Edition, Prentice Hall. 
Gendron,Y., Cooper, D. J., and Townley, B. (2006), "The construction of auditing expertise in measuring government performance", Accounting, Organisations and Society.

Goddard, A (2010), "Contemporary public sector accounting research-An international comparison of journal papers", The British Accounting Review, 42, 2, pp. 75-87.

Godfrey, A.D., Devlin, P.J., and C. Merrouche (1999): A comparative analysis of the evolution of local government accounting in Algeria and Morocco. Research in governmental and nonprofit accounting, 10, 193-208.

Godfrey,A.D., Devlin, P.J. and Merrouche, M.C., (1996), "Governmental Accounting in Kenya, Tanzania and Uganda”, Research in Governmental Nonprofit Accounting, 9, pp.193-208.

Godfrey, A.D., Devlin, P.J. and Merrouche, M.C., (2000), "Government Accounting Development within a Transitional Economy-Albania a case study", The Journal of Applied Accounting Research, 5, III, pp.52-85.

Godfrey, AD, Devlin, PJ \& Merrouche, C 2001, “A diffusion-contingency model for government accounting innovations", International Comparative Issues in

Government Accounting, pp. 279-296.

Jgore, S., Caperchione, E., and Jones, R. (2011). "Comparative International Governmental Accounting Research (CIGAR): Bridging Researching and Networking." In Jones, R. (Ed.) Public Sector Accounting, Vol. 4. SAGE. London.

Gupta, S., G. Schwartz, S. Tareq, R. Allen, I. Adenauer, K. Fletcher, and D. Last. (2008), Fiscal Management of Scaled-Up Aid (Washington: International Monetary Fund), Financial Management Reform. Greenwich, CT: Information Age Publishers.

Guthrie, J., G., Olson, O., and Humphrey, C. (1999), "Debating Developments in New Public Financial Management: The limits of global theorising and some new ways forward", Financial Accountability and Management, 15/3\&4, pp.209-228.

Guthrie, J. Humphrey, C. Jones, L.R. and Olson, O. (2005), International Public Financial Management Reform: Progress, Contradictions and Challenges. Greenwich, CT: Information Age Publishers.

Harun, H. and Robinson, P., (2010), "The adoption of accrual accounting in the Indonesian public sector". In: Tsamenyi, P.M. and Uddin, P.S. (eds). Research in Accounting in Emerging Economies, Emerald Group Publishing Limited, pp.233-250.

Hood, C. (1991), “A public management for all seasons?”, Public Administration, 69, 1, pp.3-19.

Hood, C. (1995), “The 'New Public Management' in the 1980s: Variations on a Theme”,

Accounting, Organisations and Society, 20, 2/3, pp. 93-109.

Hope, K.R. (2001), “The new public management: context and practice in Africa". International Public Management Journal, 4/x, pp. 119-134.

Hopper, T. and Mserembo, P. (2004), Public Sector Financial Reform in Malawi: PPBS in a poor country, Research on Accounting in Emerging Economies, Special Supplement 2, pp.359-383.

Hopper, T., Tsamenyi, M., Uddin, S., and Wickramasinghe, D. (2009), Management accounting in less developed countries: what is known and needs knowing, Accounting, Auditing \& Accountability Journal, 22, 3, pp. 469-514.

Hoque, Z. and Adams, C. (2011), The rise and use of balanced scorecard measures in Australian government departments: Financial Accountability \& Management, 27, 3, pp.308-332

Hoque, Z. and Hopper, T. (1994), Rationality. "Accounting and politics: a case study of management control in a Bangladeshi jute mill”, Management Accounting Research, 5, pp. 5-30.

Irvine, H. J. (2011), From go to woe. How a not-for-profit managed the change to accrual accounting, Accounting, Auditing \& Accountability Journal, 24,7, pp.824- 847.

Jones, L. R. and Kettl, D. F. (2003), "Assessing public management reform in an international context". International Public Management Review, www.ipmr.net. 4, pp.1-17. 
Jones, R. H. and Caruana, J. (2014), "Central government accounting reform in Malta: is it just an illusion? Bank of Valletta Review, No. 49, pp. 51-78

Jones, R., Lande, E., Lüder, K., and Portal, M. (2013). "A Comparison of Budgeting and Accounting Reforms in the National Governments of France, Germany, the UK, and the US". Financial Accountability and Management, 29(4): 419-441.

Jones, R. (1991). "Comparative Governmental Accounting Research," Staatswissenschaften und Staatspraxis, Vol. 4, (2): 548-552.

Kambanei, T. (2014), Management accounting and control systems in the context of public sector reforms; A case study of a government department in Papua New Guinea, PhD thesis, Faculty of Business Government and Law, University of Canberra.

Lawrence, T. B. (1999). "Institutional Strategy," Journal of Management, 25 (2), 161-188.

Lee, C. (1987), 'Accounting Infrastructure and Economic Development', Journal of Accounting and Public Policy, Vol. 6, No. 2, pp. 75-85.

Lüder, K.G. (2002), "Research in Comparative Governmental Accounting over the Last Decade-Achievements and Problems", In: Montesitos, V. and Vela, J.M. (eds), Innovations in Governmental Accounting, Boston, Kluwer Academic Publisher.

Lüder, K.G. (1992), “A contingency model of governmental accounting innovations in the politicaladministrative environment", Research in Governmental and Non-Profit Accounting, Vol. 7, pp.99127.

Manning, N. (2001), "The Legacy of New Public Management in Developing Countries." International Review of Administrative Sciences, 67, 2, pp.297-312.

Maor, M. (1999), “The paradox of managerialism”, Public Administration Review, Vol. 59, 1, pp. 518.

Mkasiwa, T. (2011), 'Accounting changes and budgeting practices in the Tanzanian central government: A theory of struggling for conformance', $\mathrm{PhD}$ thesis, University of Southampton.

Meyer, J, \& Rowan, B 1991, “Institutionalized Organisations: Formal Structure as Myth and Ceremony”, in Powell, W and DiMaggio, P (Eds.) The New Institutionalism in Organisational Analysis, The University of Chicago Press, pp. 41-62.

Mzenzi, S. (2013), 'Accounting practices in the Tanzanian Local Government Authorities (LGAs): The grounded theory of manipulating legitimacy', PhD thesis (252pp), University of Southampton.

North, D., Acemoglu, D., Fukuyama, F., and Rodrik, D. (2008), Governance, Growth, and Development Decision-Making, The World Bank.

Oliorilanto, R.H., (2008), "Contingency Factors Affecting the Adoption of Accrual Accounting in Malagasy Municipalities", International Journal of Governmental Financial Management, VIII, 1, pp.37-50.

Olson, O., C. Humphrey and Guthrie, J. (2007), Into the Shadows: A Reflection on International Developments in Public Sector Accounting, 30th Annual Congress of the European Accounting Association, 25-27 April,

Olson, O., Guthrie, J., and Humphrey, C. (1998), Global Warning: Debating International Developments in New Public Financial Management. Bergen, Norway: Cappelen Akademisk Forlag.

Olson, O. Humphrey, C. and Guthrie, J. (2001), "Caught in an Evaluatory Trap: A Dilemma for Public Services under NPFM". The European Accounting Review, 10, 3, pp.505-522.

Otley, D. (1980), "The contingency of management accounting: achievement and prognosis" Accounting, Organisations and Society, pp 413-428.

Ouda, H.A.G. (2011). "A Prescriptive Model of the Transition to Accrual Accounting in Central Government," International Journal of Government Financial Management, Alexandria, Virginia USA: International Consortium on Governmental Financial Management. Vol. X (1): 63-94.

Ouda, H.A. (2004). "Basic requirements model for successful implementation of accrual accounting in the public sector", Public Fund Digest, 4(1), pp.78-99. 
Pallot, J. (2001), “A decade in review: New Zealand's experience with resource accounting and budgeting", Financial Accountability and Management, 17, 4, pp.383-400.

Pallot, J. (1998), "The New Zealand Revolution." in Olson,O, Guthrie, J, Humphrey,C. eds. Global Warning: Debating International Developments in New Public Financial Management. Bergen: Cappelen Akademisk Forlag, pp.156-184.

Pollitt, C., and Bouckaert, G. (2000), Public Management Reform. A Comparative Analysis, Oxford: Oxford University Press.

Pollitt, C. (1995), "Justification by Works or by Faith? Evaluating the New Public Management", Evaluation, 1, 2, pp. 133-154, Sage Publication.

Porter, M.E., Stern, S. (2002), National Innovative Capacity, In: The Global Competitiveness Report 2001- 2002. New York, Oxford University Press,pp. 102- 118.

Robert P. Beschel Jr. and Mark Ahern. (2012), Public Financial Management Reform in the Middle East and North Africa: An Overview of Regional Experience, The World Bank.

Sarker, A. (2006), 'New public management in developing countries: An analysis of success and failure with particular reference to Singapore and Bangladesh', International Journal of Public Sector Management, 1, 2, pp. $180-203$.

Uddin, S, and Tsamenyi, M., (2005), 'Public sector reforms and the public interest: a case study of accounting control changes and performance monitoring in a Ghanaian state- owned enterprise', Accounting, Auditing \& Accountability, 18, 5, pp. 648- 674.

Uddin, S, and Hopper, T. (2001), 'A Bangladesh soap opera: privatisation, accounting, and regimes of control in a less developed country', Accounting, Organisations and Society, 26, 7, pp. 643-672.

Wallace, R., and Briston, R. (1993), 'Improving the Accounting Infrastructure in Developing Countries', Research in Third World Accounting, Vol. 2, pp. 201-224.

Westcott, C. (2008)," World Bank Support for Public Financial Management: Conceptual Roots and Evidence of Impact," Background Paper (Washington DC: World Bank).

Wilson, D. (2003), Strategy as decision making. In S. Cummings, and D. Wilson (Eds.), Images of strategy, Oxford: Blackwell, pp. 383- 410.

Whittington, R., and Mayer, M. (2000), The European Corporation: Strategy, Structure and Social Science, Oxford, Oxford University.

Yin R. K. (2009), Case Study Research Design and Methods ( $4^{\text {th }}$ Ed), SAGE Publications, Thousand Oaks 